\title{
Characterization of Adventitious Root Development in Sweetpotato
}

\author{
Arthur Q. Villordon ${ }^{1}$ \\ LSU AgCenter, Sweet Potato Research Station, 130 Sweet Potato Road, \\ Chase, LA 71324
}

\author{
Don R. La Bonte \\ LSU AgCenter School of Plant, Environment, and Soil Sciences, Baton \\ Rouge, LA 70803
}

Nurit Firon, Yanir Kfir, and Etan Pressman
Institute of Plant Sciences, The Volcani Center, Agricultural Research
Organization, P.O. Box 6, Bet Dagan, 50250, Israel

Amnon Schwartz

Institute of Plant Sciences and Genetics in Agriculture, Faculty of Agriculture, The Hebrew University of Jerusalem, Jerusalem, Israel

Additional index words. storage root development, storage root anatomy, Ipomoea batatas

\begin{abstract}
Adventitious roots of 'Beauregard' and 'Georgia Jet' sweetpotato were observed and anatomically characterized over a period of 60 days of storage root development. The majority of 'Beauregard' and 'Georgia Jet' adventitious roots sampled at 5 to 7 days after transplanting (DAT) possessed anatomical features (five or more protoxylem elements) associated with storage root development. The majority of 'Beauregard' $(86 \%)$ and 'Georgia Jet' $(89 \%)$ storage roots sampled at 60 to 65 DAT were traced directly to adventitious roots extant at 5 to 7 DAT. The two varieties, however, differed in the timing in which regular and anomalous cambia were formed. Regular vascular cambium development, i.e., initiation and completion, was observed in both varieties at 19 to 21 DAT. Formation of complete regular vascular cambium was negligible for 'Beauregard' $(4 \%)$ in comparison with 'Georgia Jet' $(32 \%)$ at 26 to 28 DAT. However, anomalous cambia development adjacent to xylem elements was greater in 'Beauregard' (30\%) in comparison with 'Georgia Jet' $(13 \%)$. Nearly $40 \%$ to $50 \%$ of samples in both varieties showed extensive lignification in the stele region. At 32 to 35 DAT, $62 \%$ to $70 \%$ of the adventitious roots for both varieties had either been initiated (developed anomalous cambium) or were lignified. The remaining adventitious roots showed intermediate stages of vascular cambium development. The adventitious root count increased up to 19 to 21 DAT and then remained constant up to 32 to 35 DAT. These accumulated results suggest that the initial stages of adventitious root development are critical in determining storage root set in sweetpotato.
\end{abstract}

Sweetpotato producers have high expectations every season. What they want is a uniform crop consisting of U.S. No. 1 grade storage roots (elliptical roots 8 to $23 \mathrm{~cm}$ in length and 5 to $9 \mathrm{~cm}$ in diameter) and few small or oversized grade (jumbos) roots. What producers lack is the ability to predict yield. Individual plants vary greatly in the number of storage roots that they produce.

\footnotetext{
Received for publication 18 Dec. 2008. Accepted for publication $11 \mathrm{Feb} .2009$.

This research was supported by Research Grant No. US-4015-07 from BARD, the United States-Israel Binational Agricultural Research and Development Fund.

Approved for publication by the Director of the Louisiana Agricultural Experiment Station as manuscript number 2008-260-2316.

We thank the anonymous reviewers for their thoughtful review and helpful critiques of the manuscript.

${ }^{1}$ To whom reprint requests should be addressed; e-mail avillordon@agcenter.lsu.edu.
}

This extends to entire fields, which can vary in yield by up to $50 \%$ (T. Smith, personal communication) in a given season. Why yields vary is perplexing. Production fields are often adjacent to one another and planted just days or weeks apart. The durable vegetative cuttings used to establish the crop appears homogeneous and either establishes quickly in moist, warm soils or delays its establishment until environmental conditions improve. The resulting canopies under the two scenarios appear similar; however, root development is profoundly different.

Yield variability is likely a function of variability in early transplant (cutting) establishment. Previous research attributed yield differences to cultivar, propagation material, environmental, and soil factors (Kays, 1985; Ravi and Indira, 1999). Bare-rooted transplants produced adventitious roots and some of those roots subsequently underwent changes in their growth pattern and developed into storage roots (Belehu et al., 2004; Togari, 1950; Wilson and Lowe, 1973).
Adventitious roots originated from root primordia located on the nodes as well as at the cut ends, i.e., "wound" roots (Belehu et al., 2004; Togari, 1950). These roots became fibrous roots and exhibited regular secondary growth and lignification of the stele, or storage roots, and exhibited proliferation of cambial cells that formed starch-accumulating parenchyma cells. Early anatomical studies (Artschwager, 1924; McCormick, 1916) documented that storage roots originated from adventitious roots with pentarch and hexarch steles. Togari (1950) suggested that the balance between cambium development and lignification determined final storage root count and root yield. It is the combination of a contiguous, active regular vascular cambium and proliferation and growth of anomalous cambia that enabled storage roots to add girth (Kokubu, 1973; Togari, 1950; Wilson and Lowe, 1973). Depending on the number of fibrous roots that will be induced to form storage roots, sweetpotato plants will yield either a high number (four to six per plant) of uniform and high-grade roots, e.g., U.S. No. 1, or a low number of roots that may be reduced to one very large storage root per plant or no marketable roots at all. It is unclear, however, when during root development this balance is determined and whether this may be a universal mechanism among different sweetpotato varieties.

The lack of information relating to storage root set is compounded by apparently conflicting information in the literature. For example, adventitious roots that appear shortly after transplanting have been referred to as "feeder" roots (Hernandez and Hernandez, 1969). Edmond and Ammerman (1971) classified the sweetpotato root system into two types: absorbing and storage. Such information does not reflect an accurate relationship of those adventitious roots to storage root development and it is unclear how many of those adventitious roots actually became storage roots. Also, it is unclear whether storage roots emanate from these initial adventitious roots. Hence, the objective of this study was to characterize the number, anatomical features, and developmental fate of adventitious roots initiated early after transplanting in 'Beauregard' and 'Georgia Jet' varieties.

\section{Materials and Methods}

Plant materials. 'Beauregard' and 'Georgia Jet' are the most important sweetpotato varieties grown in the United States and Israel, respectively. 'Beauregard' transplants were produced in the greenhouse (Chase, LA) by bedding storage roots in unfertilized, washed sand. The temperature in the greenhouse was maintained between 24 and $27^{\circ} \mathrm{C}$. The mean relative humidity was $60 \%$. Supplementary lighting was provided using 3000-lx white fluorescent light for $12 \mathrm{~h}$ per day. 'Georgia Jet' transplants were cut from field-grown plants in the southern Arava region, Israel. Prevailing minimum and maximum temperatures in the southern Arava 
region were 24 and $35{ }^{\circ} \mathrm{C}$, respectively, Relative humidity was $30 \%$. 'Georgia Jet' transplants were then transferred to a greenhouse maintained between 17 and $33^{\circ} \mathrm{C}$ with no supplemental light. All transplants used in the various studies had five fully opened leaves and were $\approx 21 \mathrm{~cm}$ long. Except otherwise stated, the transplants were used for the experiments detailed subsequently.

Relationship between adventitious roots and storage roots. Studies were conducted to determine the relationship between adventitious roots initiated within 5 to $7 \mathrm{~d}$ after transplanting (DAT) for 'Beauregard' (United States) and 'Georgia Jet' (Israel) and eventual storage root formation. Storage roots were defined as adventitious roots with localized swelling $(0.5 \mathrm{~cm}$ or greater) versus "pencil roots," which are uniformly thickened (Wilson and Lowe, 1973). Two tests were conducted for Beauregard; the first test was conducted in the greenhouse using greenhouse-grown 'Beauregard' transplants (10 replications). Transplants were planted in pots and carefully dug at 5 DAT and digital images were taken to document number, length, and location of adventitious roots. All adventitious roots were marked with latex paint applied with a No. 4 round brush and plants replanted in sand. After $40 \mathrm{~d}$, the transplants were carefully harvested and the storage roots were examined for the presence of paint. The second test was conducted using 'Beauregard' plants from field beds (10 replications). The field bed was fertilized with $5 \mathrm{~N}-$ $20 \mathrm{P}-20 \mathrm{~K}$ at a rate of $448 \mathrm{~kg} \cdot \mathrm{ha}^{-1}$. The beds were established on 23 Mar. 2007 and covered with 1-mil black plastic. The black plastic was removed on $26 \mathrm{Apr}$. 2007, around the time the sprouts can be seen touching the black plastic. The cuttings were established in pots grown under natural conditions. The culture medium was unfertilized, washed sand. A sprinkler attached to a timer was used to irrigate the plants daily $(\approx 0.6 \mathrm{~cm})$. The transplants were planted on 29 June 2007, and plants were dug and adventitious roots marked 7 DAT, before replanting. The plants were harvested 60 DAT and storage roots were examined for presence of paint. In Israel, the test was conducted in the greenhouse using field-grown 'Georgia Jet' transplants (14 replications). Transplants were planted in pots and carefully dug at 7 DAT. All adventitious roots were marked with paint as described previously, before replanting. After $65 \mathrm{~d}$, the transplants were harvested and storage roots were examined for the presence of paint.

Anatomical features of 5- to 7-d-old adventitious roots. Thirty 'Beauregard' transplants were planted (two to three nodes deep) in 25.4-cm pots filled with unfertilized, washed sand. The pots were watered to field capacity once everyday. At $5 \mathrm{~d}$, adventitious roots were harvested, placed in distilled water, and sectioned immediately using a razor blade under a stereoscope. Transverse sections of 133 adventitious roots 8 to $15 \mu \mathrm{m}$ thick were stained with toluidine blue and observed under a microscope. Digital micro- graphs were taken with a Motic Cam 352 (Motic Instruments Inc., British Columbia, Canada). Twenty 'Georgia Jet' transplants were planted (two nodes deep) in $17-\mathrm{cm}$ pots filled with unfertilized, washed sand. The pots were watered to field capacity once each day with a $1: 10$ diluted liquid $7 \mathrm{~N}-3 \mathrm{P}-7 \mathrm{~K}$ fertilizer (Shefer No. 3; Fertilizers and Chemicals Ltd., Haifa, Israel). Adventitious roots were harvested after $7 \mathrm{~d}$ and assayed as detailed previously for 'Beauregard' transplants, except that sections were immersed for $1 \mathrm{~min}$ in $10 \mathrm{M} \mathrm{NaOH}$ followed by $1 \mathrm{~min}$ in $50 \%$ acetic acid before staining with toluidine blue. Protoxylem element number was classified into tetrarch, pentarch, hexarch, septarch, octarch, ennearch, and decarch for 'Beauregard' and 'Georgia Jet'.

Anatomical features of developing adventitious roots. Thirty 'Beauregard' and 'Georgia Jet' plants were established in pots and 10 plants were sampled 5, 19, 26, and 32 DAT in the United States and 7, 21, 28, and 35 DAT in Israel. For each sampling date, all adventitious roots were serially sectioned and observations were generally recorded from the proximal $3-\mathrm{cm}$ section of the root. Where necessary, lignification was confirmed by
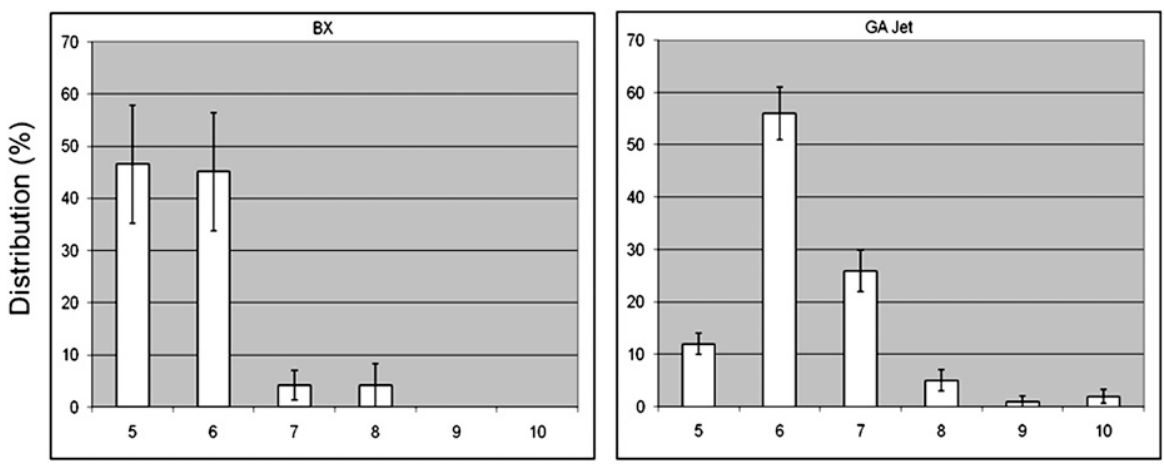

Protoxylem element number

Fig. 1. Distribution of adventitious root protoxylem element number in 'Beauregard' (BX) and 'Georgia Jet' (GA Jet) transplants sampled at 5 and $7 \mathrm{~d}$ after transplanting, respectively. 'Beauregard' transplants were obtained from bedded roots, whereas 'Georgia Jet' vine cuttings were obtained from field-grown plants. The number of transplants sampled was 30 and 20 for BX and Ga Jet, respectively; the error bars indicate the SE of the mean.
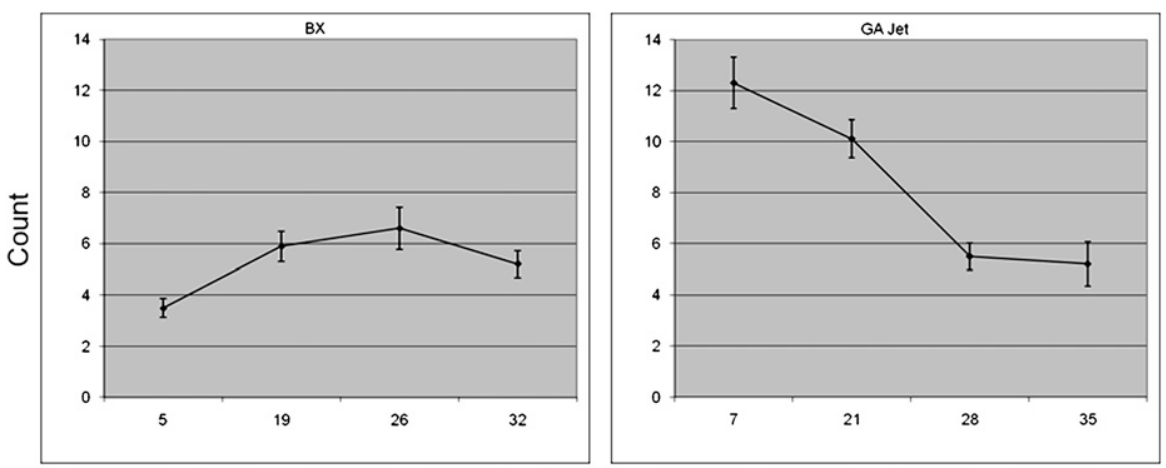

Days after transplanting

Fig. 2. Adventitious root count in 'Beauregard' (Bx) and 'Georgia Jet' (GA Jet) transplants sampled at various dates. 'Beauregard' transplants were obtained from bedded roots, whereas 'Georgia Jet' vine cuttings were obtained from field-grown plants. The number of transplants sampled was 10 for both BX and Ga Jet; the error bars indicate the SE of the mean. 
up to 9 weeks after transplanting. Results showed that $80 \%$ of the greenhouse-grown 'Beauregard' storage roots had paint markings (33 of 41 total storage roots), whereas $86 \%$ (36 of 42 storage roots) had paint markings when potted plants were grown under natural conditions. A high proportion $(89 \%)$ of 'Georgia Jet' storage roots had paint markings. These results indicated that, in both 'Beauregard' and 'Georgia Jet', a high proportion of the storage roots developed from adventitious roots that formed within the first week after planting.

Anatomical features of 5- to 7-d-old adventitious roots. In 'Beauregard', the number of primary xylem poles varied between five and eight; in 'Georgia Jet', the range was from five to 10 (Fig. 1). The outer tracheary elements at each pole represent protoxylem, whereas the inner metaxylem represents two or three large metaxylem elements in the central part of the vascular cylinder.

Root central cylinders with a vascular system consisting of pentarch and hexarch arrangements accounted for a combined $90 \%$ of the total number of 'Beauregard' roots 5 DAT (Fig. 1). The arrangements of the central cylinder in the remaining roots were septarch $(5 \%)$ and octarch (5\%). In contrast, hexarch and septarch steles accounted for $82 \%$ of the total number of 'Georgia Jet' samples. The remaining roots were pentarch (12\%), octarch (5\%), ennearch (1\%), and decarch (2\%) (Fig. 1).

Anatomical features of developing adventitious roots. Adventitious roots were characterized at 5, 19, 26, and 32 DAT and 7, 21, 28, and 35 DAT for 'Beauregard' and 'Georgia Jet', respectively. The adventitious root counts summed across the proximal two nodes varied for the two varieties at 5 to 7 DAT; 'Beauregard' averaged 3.5 adventitious roots per plant, whereas 'Georgia Jet' had 12.3 (Fig. 2). The adventitious root count was similar in the two varieties at 26 to 35 DAT.

'Beauregard' and 'Georgia Jet' roots sampled at three developmental stages showed various anatomical features related to root thickening. Root thickening started as the initiation of the vascular cambium from undifferentiated procambium cells between the primary xylem and phloem (Fig. 3A). The meristematic activity of the vascular cambium led to the production of secondary xylem and phloem and the gradual completion of a continuous cambial ring (regular vascular cambium) (Fig. 3B).

The parenchyma cells that resumed meristematic activity around the trachea were defined by Wilson and Lowe (1973) as primary cambium when the repeated cell division occurred around trachea of the primary xylem. Secondary cambia were defined as repeated cell divisions around the trachea of the secondary xylem. The repeated division of newly formed cambia [defined by Wilson and Lowe (1973) as anomalous cambium] led to the formation of rows of thinwalled parenchyma cells that formed the storage tissue of the swelling root.

The formation of primary and secondary cambia (anomalous cambium) encircling
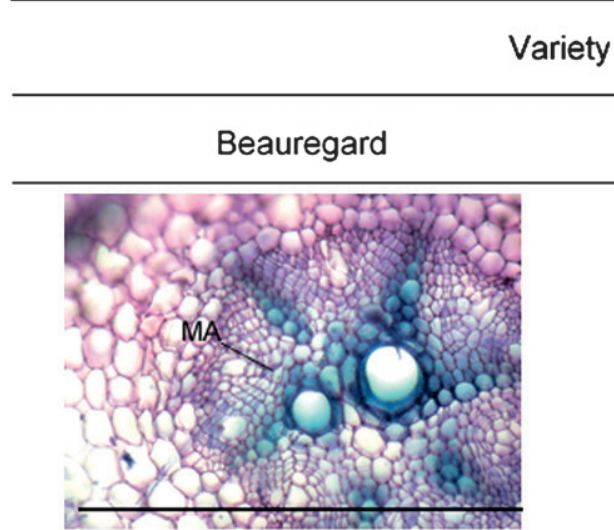

A

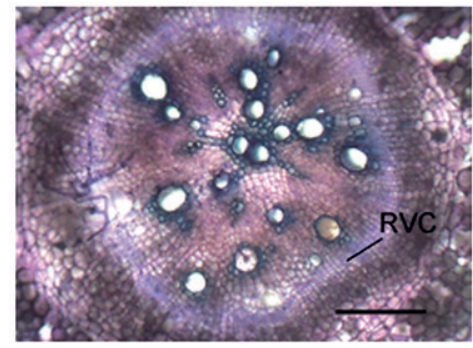

B
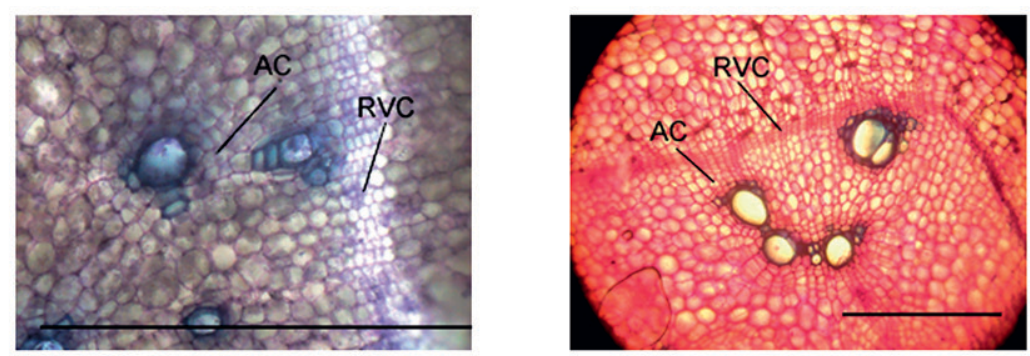

C
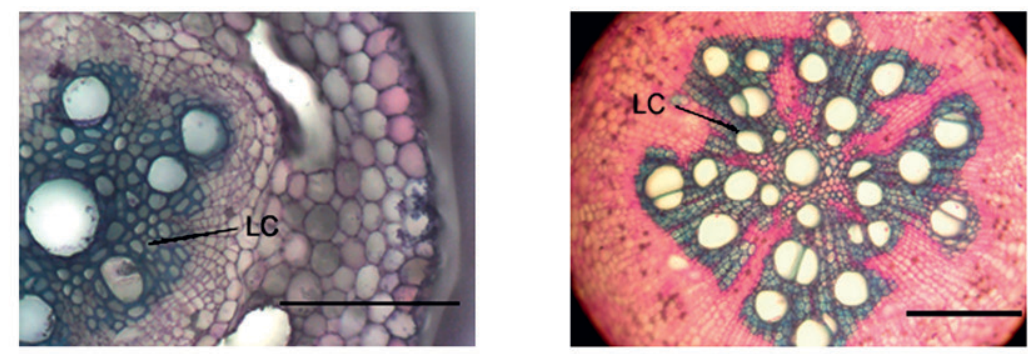

D

Fig. 3. Transverse sections derived from different locations of 'Beauregard' and 'Georgia Jet' sweetpotato adventitious roots showing (A) initiation of vascular cambium, (B) completion of vascular cambium development, (C) appearance of anomalous cambium, and (D) lignification of the stele section. The adventitious root samples were harvested starting at $26 \mathrm{~d}$ after transplanting and sections were removed $3 \mathrm{~cm}$ from the proximal end. $\mathrm{RVC}=$ complete regular vascular cambium (following terminology by Wilson and Lowe, 1973); MA = meristematic activity; $\mathrm{AC}=$ anomalous cambium; $\mathrm{LC}=$ lignified cells). 'Beauregard' transplants were obtained from bedded roots, whereas 'Georgia Jet' vine cuttings were obtained from field-grown plants. Scale bars $=0.5 \mathrm{~mm}$.

many of the primary and secondary xylem elements, respectively (Fig. 3C), was the first clear sign of the developmental transition of the root to a storage root. Intensive lignification of the parenchyma cell walls of the pith and pith ray parenchyma usually occurred in roots that did not develop into storage roots (Fig. 3D). Development of the vascular cambium, i.e., initiation and completion of a regular vascular cambial ring, was observed in both varieties at 19 to 21 DAT (Fig. 4A). During this period, $49 \%$ of 'Beauregard' (19 DAT) and $83 \%$ of 'Georgia Jet' (21 DAT) adventitious roots exhibited initiation of regular vascular cambium. Storage root initiation (secondary cambium activity around the 

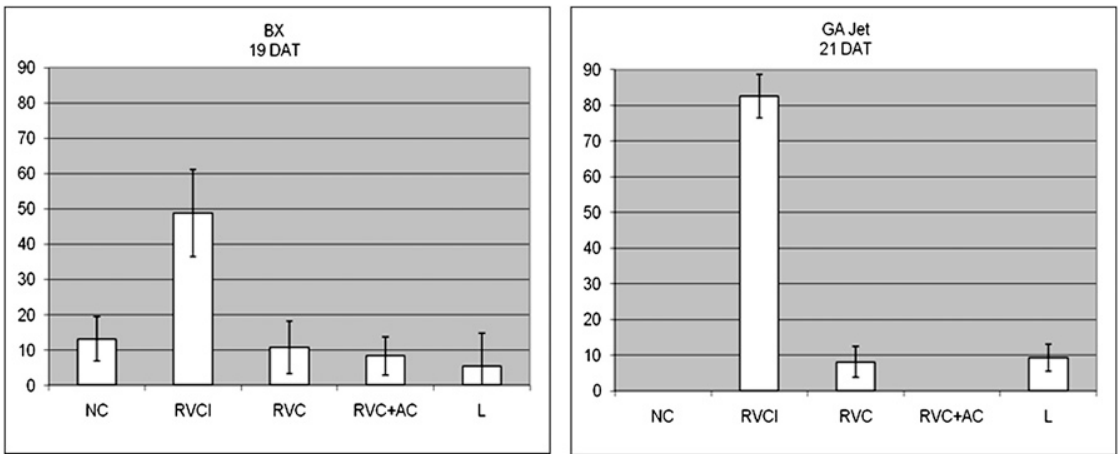

A
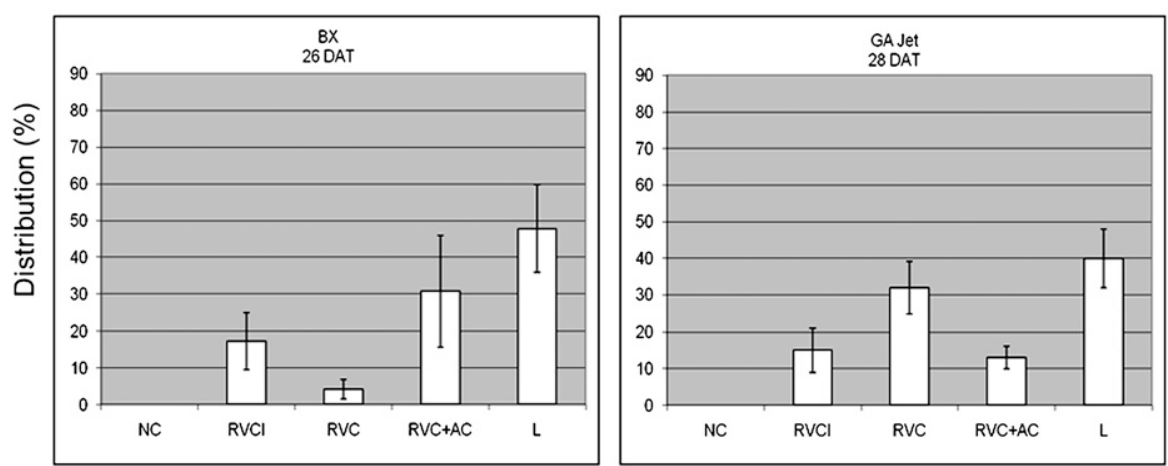

B
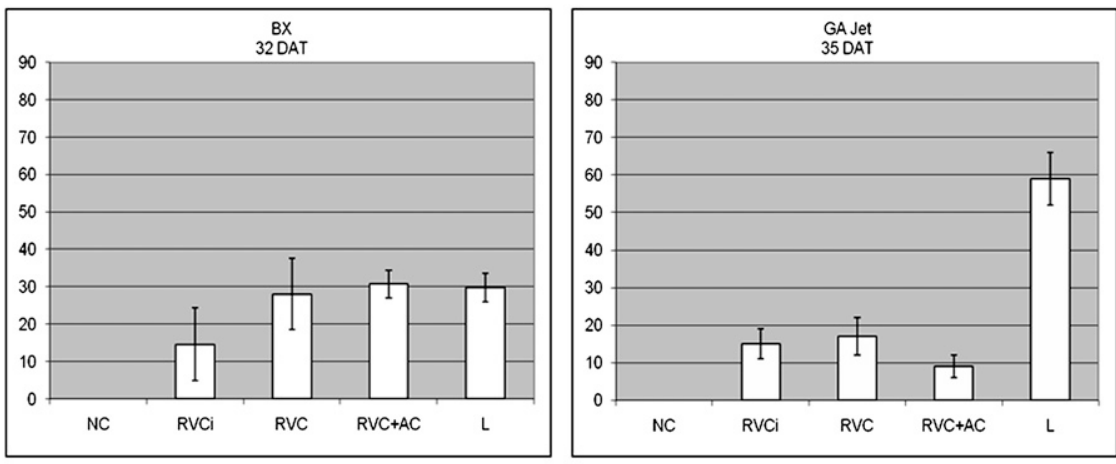

C

\section{Anatomical feature}

Fig. 4. Distribution of adventitious root anatomical features among 'Beauregard' (BX) and 'Georgia Jet' (GA Jet) transplants sampled at the following days after transplanting (DAT): 19 and 21 (A), 26 and 28 (B), and 32 and $35(\mathbf{C})$, respectively. $\mathrm{NC}=$ no cambium activity detected; $\mathrm{RVCI}=$ primary cambium activity, appearance of cambium initials and initial growth of cambium; $\mathrm{RVC}=$ complete regular vascular cambium (following terminology by Wilson and Lowe, 1973); RVC $+\mathrm{AC}=$ completed RVC and appearance of anomalous cambium; $L=$ lignified stele. 'Beauregard' transplants were obtained from bedded roots, whereas 'Georgia Jet' vine cuttings were obtained from field-grown plants. The number of transplants sampled was 10 for both BX and Ga Jet in all sampling dates; the error bars indicate the SE of the mean.

xylem elements) was observed in $8 \%$ of 'Beauregard' samples, whereas none was observed for 'Georgia Jet'. At 26 to 28 DAT, formation of complete regular vascular cambium was negligible for 'Beauregard' $(4 \%)$ in comparison with 'Georgia Jet' (32\%) (Fig. 4B). In this period, the proportion of 'Beauregard' samples that developed secondary cambium activity $(30 \%)$ was twice that of 'Georgia Jet' (13\%). In the same period, $40 \%$ to $48 \%$ of 'Georgia Jet' and 'Beauregard' samples were lignified. At 32 and 35 DAT, adventitious roots of nearly $62 \%$ of 'Beauregard' and $70 \%$ of 'Georgia Jet', respectively, were either lignified or had become initiated
(Fig. 4C). In the same period, the remainder of 'Beauregard' and 'Georgia Jet' adventitious roots either showed complete regular vascular cambium ('Beauregard' = 28\%, 'Georgia Jet' = $17 \%$ ) or were in various stages of primary vascular cambium development ('Beauregard' and 'Georgia Jet' $=15 \%$ ).

\section{Discussion}

The majority of 'Beauregard' and 'Georgia Jet' sweetpotato adventitious roots that were initiated as early as 5 to 7 DAT possessed the anatomical characteristic [five or more protoxylem poles (Artschwager, 1924; Belehu et al., 2004; McCormick, 1916; Togari, 1950; Wilson and Lowe, 1973)] associated with development into storage roots. Furthermore, our data suggest that adventitious roots extant at 5 to 7 DAT accounted for up to $86 \%$ and $89 \%$ of the storage roots formed in 'Beauregard' and 'Georgia Jet', respectively, 9 weeks after transplanting. Assuming all the paint markings remained on the adventitious roots, the remaining unmarked storage roots likely originated from adventitious roots that were initiated after 5 to $7 \mathrm{~d}$. Our findings suggest that adventitious roots initiated as early as 5 to 7 d were not merely "feeder" or "fibrous" roots; rather, these adventitious roots represented a pool of potential storage roots that ultimately accounted for $85 \%$ to $89 \%$ of storage roots under our experimental conditions. Previous reports suggested that storage root initiation did not start until 42 DAT (Onwueme, 1978) or as late as 60 DAT (Edmond and Ammerman, 1971).

Our results suggest that transplant-related as well as environmental and management variables at transplanting could have a significant impact on early storage root development. For instance, Kano and Nagata (1999) documented that virus-infected sweetpotatoes initiated fewer but larger roots in comparison with virus-free plants. They also observed that the pith and vascular bundle cylinder at the node were larger in the virusfree plants in comparison with virus-infected plants. It is well documented that virus infection can reduce the yield of sweetpotatoes (Carroll et al., 2004; LaBonte et al., 2004). The use of sand culture medium in our studies allowed us to extract and examine adventitious root samples with minimal damage. This method can be adopted to include experimental treatments such as fertilizer, herbicides, insecticides, and plant growth regulators targeting the first week of growth.

Ravi and Indira (1999) reviewed storage root initiation in sweetpotatoes and concluded that the timing of this event varied widely among cultivars and took place from 7 to 91 DAT. Under our experimental conditions, anomalous cambia (storage root initiation) began to appear at 19 and 21 DAT in 'Beauregard' and 'Georgia Jet', respectively. These two varieties differed in the magnitude and timing of the development of anomalous and regular vascular cambia. 'Beauregard' formed anomalous cambia to a greater extent earlier than 'Georgia Jet'. In contrast, regular vascular cambium formation was delayed in 'Beauregard' in comparison with 'Georgia Jet'. Lowe and Wilson (1974a, 1974b) showed that some cultivars reduced their dependence on the formation of anomalous cambia for storage root initiation by developing a more active regular vascular cambium. They suggested that storage root shape and size were impacted by the differential activities of the two cambia. In 'Beauregard', $47 \%$ of adventitious roots were lignified at 26 DAT. In 'Georgia Jet', nearly $60 \%$ of adventitious roots were lignified at 35 DAT. This indicates that under our experimental conditions, lignification reduced yield potential by nearly half at 26 and 35 
DAT in 'Beauregard' and 'Georgia Jet', respectively. Togari (1950) stated that the environmental conditions during the first 20 DAT were important in determining storage root initiation. Togari (1950) documented that excessive applications of nitrogen fertilizer in combination with reduced soil aeration decreased cambium activity and increased lignification. This indicated that management and environmental variables during the first 35 DAT contributed to the proportion of adventitious roots that were initiated and became lignified. Other than the published work of Togari (1950), very little is known about the conditions or mechanisms that cause lignification in developing sweetpotato adventitious roots. Wilson and Lowe (1973) cited an unpublished study that documented that pith and cortical cells of storage roots did not exhibit peroxidase activity, a normal requirement for lignin biosynthesis. Information about management and environmental variables that predispose adventitious roots to lignification might be used to develop methods or modify existing management practices to reduce risk associated with lignification thereby increasing potential storage root yield in 'Beauregard' and 'Georgia Jet'.

There were considerable differences in the initial ( 5 to 21 DAT) adventitious root count in the proximal two nodes of 'Beauregard' and 'Georgia Jet'. The initial 'Beauregard' root count was relatively low and peaked at 26 DAT; 'Georgia Jet' started with a higher count and decreased thereafter. A similar trend was reported by Lowe and Wilson (1974a) among West Indian sweetpotato varieties. Their report showed that total root number generally peaked at 14 to 28 DAT and subsequently decreased in five of the six varieties that they studied. There was no information about the number of nodes in the study by Lowe and Wilson (1974a). Nakatani and Komeichi (1991) also reported variability in root counts of thick and "tuberous" roots in 'Koganesengan' and 'Beniako' (basal three nodes) varieties and I. trifida (basal two nodes). However, their measurements did not begin until the fourth week after planting and the period of maximum root count varied among the two varieties and I. trifida. We are unaware of any published work that explains the variability of adventitious root numbers in sweetpotatoes, especially within the first week of transplanting. In Arabidopsis, Konishi and Sugiyama (2003) documented that auxin and temperature influenced the formation of adventitious roots in temperature-sensitive Arabidopsis mutants. Takahashi et al. (2003) also documented sugar-induced adventitious rooting in Arabidopsis seedlings. Sorin et al. (2005) studied Arabidopsis mutants with altered adventitious root formation capabilities and stated that adventitious rooting was a quantitative trait controlled by environmental (light) and endogenous factors. Nakatani and Komeichi (1991) reported variability in indole acetic acid (IAA) levels over a period of 15 weeks in adventitious roots of 'Koganesengan' and 'Beniako' sweetpotatoes but did not correlate the variability in the number of roots with the temporal variation in IAA.

\section{Conclusion}

The majority of adventitious roots that were initiated as early as 5 to 7 DAT possessed the anatomical characteristics associated with storage root development. These newly initiated adventitious roots accounted for nearly $86 \%$ to $89 \%$ of the total storage root count at 60 to $65 \mathrm{DAT}$. At 32 to 35 DAT, nearly $60 \%$ to $68 \%$ of the adventitious roots were either lignified or developed anatomical features that are prerequisite to storage root formation. The data suggest that in 'Beauregard' and 'Georgia Jet', the period spanning 5 to 35 DAT was critical in determining whether adventitious roots became lignified or initiated as storage roots. The confounding environmental and management variables in the experimental treatments represented a major limitation of the current work. Future studies can focus on locationspecific environmental and management variables within this period that either reduce lignification or promote storage root initiation. Such studies could potentially reduce field-level variability associated with storage root yields in sweetpotatoes and serve as a basis for developing phenological models for optimizing storage root formation.

\section{Literature Cited}

Artschwager, E. 1924. On the anatomy of sweet potato root with notes on internal breakdown. J. Agr. Res. 23:157-166.

Belehu, T., P.S. Hammes, and P.J. Robbertse. 2004. The origin and structure of adventitious roots in sweetpotato (Ipomoea batatas). Aust. J. Bot. 52:551-558.

Carroll, H., A. Villordon, C. Clark, D. LaBonte, and M. Hoy. 2004. Studies on Beauregard sweetpotato clones naturally infected with viruses. Intl. J. Pest Manage. 50:101-106.

Edmond, J.B. and G.R. Ammerman. 1971. Sweetpotatoes: Production, processing, marketing. AVI Publ. Co., Westport, CT.

Esau, K. 1965. Plant anatomy. 2nd Ed. John Wiley \& Sons, Inc., New York, NY

Hernandez, T.P. and T. Hernandez. 1969. Irrigation to increase sweet potato production, p. 36. In: Tai, E.A., W.B. Charles, and P.H. Paynes (eds.). Proc. Int. Symp. Trop. Root Crops; St. Augustine, Trinidad; 2-8 Apr. 1967. Vol. 1.

Kano, Y. and R. Nagata. 1999. Comparison of the rooting ability of virus infected and virus-free cuttings of sweet potatoes (Ipomoea batatas Poir.) and an anatomical comparison of roots. J. Hort. Sci. Biotechnol. 74:785-790.

Kays, S.J. 1985. The physiology of yield in the sweet potato, p. 79-132. In: Bouwkamp, J. (ed.). Sweetpotato products: A natural resource for the tropics. CRC Press, Boca Raton, FL.

Kokubu, T. 1973. Thremmatological studies on the relationship between the structure of tuberous root and its starch accumulating function in sweet potato varieties. Bull. Fac. Agr. Kagoshima Univ. 22:1-126.

Konishi, M. and M. Sugiyama. 2003. Genetic analysis of adventitious root formation with a novel series of temperature-sensitive mutants of Arabidopsis thaliana. Development 130:56375647.

LaBonte, D., C. Clark, A. Villordon, J. Cannon, M. Hoy, M. Sistrunk, E. Freeman, and G. Roberts. 2004. Yield of four generations of virus-tested sweetpotato. HortTechnology 14:320-322.

Lowe, S.B. and L.A. Wilson. 1974a. Comparative analysis of tuber development in six sweet potato [Ipomoea batatas (L.) Lam.] cultivars. 1. Tuber initiation, tuber growth and partition of assimilate. Ann. Bot. (Lond.) 38:307-317.

Lowe, S.B. and L.A. Wilson. 1974b. Comparative analysis of tuber development in six sweet potato [Ipomoea batatas (L.) Lam.] cultivars 2. Interrelationships between tuber shape and yield. Ann. Bot. (Lond.) 38:319-326.

McCormick, F.A. 1916. Notes on the anatomy of the young tuber of Ipomoea batatas Lam. Bot. Gaz. 61:388-398.

Nakatani, M. and M. Komeichi. 1991. Changes in the endogenous level of zeatin riboside, abscisic acid and indole acetic acid during formation and thickening of tuberous roots in sweet potato. Jpn. J. Crop. Sci. 60:91-100.

Onwueme, I.C. 1978. Tropical tuber crops. John Wiley and Sons Ltd., Chichester, NY.

Ravi, V. and P. Indira. 1999. Crop physiology of sweet potato, p. 277-316. In: Janick, J. (ed.). Horticultural reviews. Vol. 23. John Wiley \& Sons, Inc., New York, NY.

Sorin, C., J.D. Bussell, I. Camus, K. Ljung, M. Kowalczyk, G. Geiss, H. McKhann, C. Garcion, H. Vaucheret, G. Sandbert, and C. Bellini. 2005. Auxin and light control of adventitious rooting in Arabidopsis require ARGONAUTE1. Plant Cell 17:1343-1359.

Takahashi, F., K. Sato-Nara, K. Kobayashi, M. Suzuki, and H. Suzuki. 2003. Sugar-induced adventitious roots in Arabidopsis seedlings. J. Plant Res. 116:83-91.

Togari, Y. 1950. A study of tuberous root formation in sweet potato. Bul. Nat. Agr. Expt. Sta. Tokyo 68:1-96.

Wilson, L.A. and S.B. Lowe. 1973. The anatomy of the root system in West Indian sweet potato [Ipomoea batatas (L.) Lam.] cultivars. Ann. Bot. (Lond.) 37:633-643. 